\title{
REFLEXÕES SOBRE USO DOS PRINCÍPIOS BÁSICOS DE ERGONOMIA VISUAL PARA PROFISSIONAIS DA EDUCAÇÃO A DISTÂNCIA
}

\section{REFLECTIONS ON THE BASIC PRINCIPLES OF VISUAL ERGONOMICS FOR EDUCATION PROFESSIONALS DISTANCE}

\author{
Francine Medeiros Vieira ${ }^{1}$, Esp. \\ Gilson Braviano ${ }^{2}$, Dr.
}

(1) Universidade Federal de Santa Catarina e-mail: francinemedeiros@gmail.com.br

(2) Universidade Federal de Santa Catarina e-mail: gilson@cce.ufsc.br

Palavras-chave: Comunicação Virtual. Ambientes Virtuais de Aprendizagem. Ergonomia Visual.

Este artigo tem como objetivo explicitar a importância de um curso de capacitação em Princípios Básicos de Ergonomia Visual para que profissionais da Educação a Distância possam elaborar mensagens esteticamente mais agradáveis e coerentes, tanto com o layout quanto com o conteúdo. Foi realizada uma análise de Ambientes Virtuais de Aprendizagem, apontando carência no aprimoramento técnico em diversos elementos comunicacionais. As reflexões geradas neste artigo, sobre um curso dessa natureza, conduzem à crença na melhoria da formação de profissionais aptos na elaboração de mensagens e na apresentação de informações, e assim, gerando um aprimoramento na comunicação virtual, no trato com alunos, potencializando a eficiência do processo.

Key-words: Virtual Communication. Virtual Learning Environments. Visual Ergonomics.

This article aims to clarify the importance of a training course in Basic Principles of Visual Ergonomics so that Distance Education professionals can elaborate aesthetically pleasing and coherent messages, both with layout and content. An analysis of Virtual Learning Environments was carried out, pointing out the lack of technical improvement in several communication elements. The reflections generated in this article, on a course of this nature, lead to the belief in the improvement of the training of professionals able to elaborate messages and in the presentation of information, and thus, generating an improvement in the virtual communication, dealing with students, potentializing efficiency of the process. 
$16^{\circ}$ Ergodesign - Congresso Internacional de Ergonomia e Usabilidade de Interfaces Humano Tecnológica: Produto, Informações Ambientes Construídos e Transporte

$16^{\circ}$ USIHC - Congresso Internacional de Ergonomia e Usabilidade de Interfaces Humano Computador

CINAHPA | 2017 - Congresso Internacional de Ambientes Hipermídia para Aprendizagem.

\section{Introdução}

A comunicação em meios virtuais, com a popularização da internet, se tornou algo comum e prático. Basta que os usuários tenham um dispositivo eletrônico, como celular, tablet, Smart $\mathrm{TV}$, computador de mesa ou notebook, e acesso à internet para começarem a receber e compartilhar informações. Esta nova realidade advém dos avanços tecnológicos que surgiram após a web 2.0 (rede social colaborativa), os quais revolucionaram a postura das pessoas quanto ao seu uso, consolidando ainda mais o seu sucesso

(AMOROSO, 2008).

Na web 2.0, a partir de 2004, foi permitido aos usuários interagirem de tal forma que se sentissem autores, pois poderiam participar ativamente na construção virtual e coletiva do conhecimento, editando, comentando e publicando textos, fotos e vídeos em fóruns, blogs, websites e mídias sociais (LITTO e FORMIGA, 2012). Desta forma, devido à facilidade em comunicar, compartilhar $\mathrm{e}$ reutilizar conteúdos na web, não raro, nos deparamos com textos e sites contendo erros ortográficos, mal formatados e construídos sem atenção ao trato visual. Tais fragilidades percebidas nesta interação entre usuários resultam, entre outras coisas, da falta de recomendações de uso, o que é agravado com a forma desregrada como a internet vem sendo utilizada nos últimos anos. Portanto, seria de grande valia a disponibilização de instruções voltadas aos usuários para garantir uma web de maior qualidade no futuro.

Dentro deste contexto, o processo de conscientização para adoção de uma postura diferente deve ser calcado em princípios ergonômicos para a comunicação na web, e pode gerar bons resultados a médio e longo prazo, desde que sejam levados em conta aspectos educacionais.

Este artigo busca gerar reflexões teóricas, associadas à identificação de falhas em ambiente virtuais de aprendizagem, de modo a salientar a importância na criação e oferta de cursos de capacitação em Princípios Básicos de Ergonomia
Visual, direcionados aos profissionais do ensino a distância.

\section{Comunicação Virtual e Ambientes Virtuais de Aprendizagem (AVAs)}

A utilização massiva das Tecnologias da Informação e Comunicação (TICs) contribui para que, a todo o momento, milhares de dados e informações sejam bombardeados, ficando difícil identificar e selecionar o conteúdo que é realmente útil. Esse excesso de informações, muitas vezes, gera ruídos e poluição visual, que somados à falta de zelo na apresentação dos conteúdos e mensagens, pode provocar falhas ou desconforto na comunicação.

Segundo Grujic (2008), a imagem de uma pessoa ou empresa na internet é tudo, implicando que o cuidado com o qual se apresenta e escreve pode definir uma reputação, influenciando positiva ou negativamente na imagem do indivíduo ou da instituição. Este cuidado pode ser ampliado aos Ambientes Educacionais, ensejando a capacitação dos colaboradores para evitar que vícios da internet $\mathrm{e}$ falhas na comunicação virtual gerem impactos negativos no processo ensinoaprendizagem. Esta é uma situação muito pertinente na modalidade de ensino a distância, que se expande a passos largos devido à rápida disseminação do uso da internet.

O ensino a distância está vivenciando a Pedagogia da abundância, assim denominada por Weller (2011). A falta de conteúdos e recursos, antigamente apontados como uns dos principais problemas da educação, hoje está sendo superada pelas características estruturais da Sociedade da Informação e do Conhecimento, tais como:

“(1) o conteúdo é livre, (2) o conteúdo é abundante, (3) o conteúdo é variado, (4) o compartilhamento é fácil, (5) a aprendizagem tem base social, (6) as conexões são simples, (7) a organização é fácil e barata, (8) se 


\section{$16^{\circ}$ \\ ERGODESIGN USIHC CINAHPA}

origina em um sistema generativo e (9) o conteúdo também pode ser gerado pelo usuário." (SANTAROSA, 2014, p.169)

Desta forma, a comunicação e a construção do conhecimento nos AVAs precisam ser mediadas e estrategicamente planejadas para que o aluno seja visualmente atraído e motivado a permanecer focado na aprendizagem.

Os AVAs têm muitos recursos tecnológicos (e-mails, chats, fóruns, glossários, midiatecas e salas de estudo, por exemplo) para aproximar alunos e professores, conforme ressalta Martins (2001), e o cuidado ao enviar mensagens, feedbacks e postar orientações de estudo aos alunos é fundamental, para reduzir possíveis ruídos na comunicação e gerar mais empatia. Tais medidas contribuem para a credibilidade da instituição que oferta esta forma de ensino.

Neste sentido, a formação em ergonomia visual tem potencial para contribuir com as instituições que atuam nesta área, capacitando seus profissionais a usarem recomendações básicas para que a comunicação em meios virtuais ocorra de modo mais formal e estratégico. É neste contexto de valorização e disseminação da EaD que ocorre a necessidade de inserção de novos profissionais capacitados para atuarem com qualidade técnica no trato das informações na web, plenamente envolvidos na comunicação educacional e virtual.

\section{Recomendações de Ergonomia Visual}
"A ergonomia (ou Fatores Humanos) é uma disciplina científica relacionada ao entendimento das interações entre os seres humanos e outros elementos ou sistemas, e à aplicação de teorias, princípios, dados e métodos a projetos a fim de otimizar o bem- estar humano e o desempenho global do sistema." (ABERGO, 2000)

No contexto da ergonomia de interface, o bemestar humano está diretamente ligado ao conforto visual. Este, por sua vez, pode ser alcançado com os resultados das pesquisas pautadas em novas $16^{\circ}$ Ergodesign - Congresso Internacional de Ergonomia e Usabilidade de Interfaces Humano Tecnológica: Produto, Informações Ambientes Construídos e Transporte

$16^{\circ}$ USIHC - Congresso Internacional de Ergonomia e Usabilidade de Interfaces Humano Computador

CINAHPA | 2017 - Congresso Internacional de Ambientes Hipermídia para Aprendizagem. tecnologias e por meio da adequação técnica do layout, permitindo atrair e agradar de forma segura e funcional (ABRAHÃO, 2009). Sobre este assunto, Ambrose (2012) afirma que informar, orientar, entreter, guiar e cativar são funções essenciais a serem definidas para dar finalidade ao layout. $\mathrm{O}$ autor ainda afirma, que "o objetivo principal do layout é apresentar os elementos textuais e visuais de uma forma que o leitor os receba com o mínimo de esforço." (AMBROSE, 2012, p.10). Para Agner (2009), o ser humano é o elemento central dos sistemas interativos, e é fundamental conhecer suas necessidades, objetivos e características. Desta forma, a compreensão de como o ser humano percebe e reage aos estímulos visuais é uma atividade técnica mensurável que contribui para a área específica de conhecimento denominada 'ergonomia cognitiva' (BATISTA, 2006).

Segundo Ambrose (2012), para garantir a qualidade técnica da comunicação visual deve-se conhecer alguns princípios básicos do layout na inserção de elementos em uma página: colunas e espaços; escala; alinhamento; imagens; hifenização e justificação; ritmo; hierarquia da informação e rótulos; arranjo e pontos de entrada. Já Gomes (2010) defende a utilização do sistema técnico de leitura ergonômica, que, segundo ele, é um conjunto de conceitos aplicável a qualquer análise ou projeto ergonômico, sobre qualquer tipo de produto ou sistema de objetos, no seu todo ou em partes específicas.

O Sistema técnico de leitura ergonômica, sugerido por Gomes (2010), quanto à percepção visual e recebimento de informações, baseia-se na definição de quatro códigos visuais:

1. Tipográfico: que diz respeito à família de letras, números e outros sinais e caracteres; 2. Morfológico: organização visual da informação, diagramação e Leis da Gestalt (Unidade, Segregação, Unificação, Fechamento, Continuidade, Proximidade, Semelhança e Pregnância da forma);

3. Cromático: definição e utilização das cores; e

4. Tecnológico: Processos de produção, reprodução e transmissão da informação. 


\section{$16^{\circ}$ \\ ERGODESIGN USIHC CINAHPA}

$16^{\circ}$ Ergodesign - Congresso Internacional de Ergonomia e Usabilidade de Interfaces Humano Tecnológica: Produto, Informações Ambientes Construídos e Transporte

$16^{\circ}$ USIHC - Congresso Internacional de Ergonomia e Usabilidade de Interfaces Humano Computador

CINAHPA | 2017 - Congresso Internacional de Ambientes Hipermídia para Aprendizagem.
Sobre a tipografia, ainda, Gomes (2010) apresenta a legibilidade e a leiturabilidade da informação visual como elementos básicos para uma boa Ergonomia Visual. A legibilidade diz respeito à facilidade na recepção e identificação de uma informação, em comparação com um padrão armazenado na memória do indivíduo, e está relacionada com: o contraste figura-fundo, diagramação, cores, dimensão e organização visual de tipografias, gráficos, grifos, e outros sinais. Já a leiturabilidade diz respeito à qualidade que torna possível reconhecer e ler os grupamentos, como palavras e frases. Algumas recomendações que abrangem um campo imenso de possibilidades, elencadas por Gomes (2010), devem ser priorizadas no desenvolvimento de informações que serão expostas na internet.

Quanto à tipografia, recomenda-se:

- Evitar o uso de caixa alta em texto longo e de texto longo em corpo pequeno, pois tornam a leitura cansativa e desagradável.

- Aplicar alinhamentos, espaçamentos, tamanhos legíveis e proporcionais entre títulos, subtítulos e corpo de texto, para alcançar uniformidade e equilíbrio na composição.

- Usar letras e caracteres sem serifa, de modo a facilitar a compreensão e a correlação rápida da informação.

- Analisar a necessidade de letras e caracteres fantasia, fontes rebuscadas e outros recursos como os atributos itálicos, negrito, sublinhados, adornos, filetes, colchetes etc., que possam prejudicar a legibilidade da informação.

- Utilizar, de preferência, uma mesma família que garanta a harmonia do padrão tipográfico das informações apresentadas.

- Associar os textos escritos com as imagens, pois o texto ganha maior força e intensidade e a informação visual é reforçada naturalmente.

- Avaliar a facilidade de leitura na aplicação de um texto em um fundo; texto na cor verde, sobre um fundo vermelho, por exemplo, é considerado ilegível.
- Aplicar contorno no texto numa cor apropriada quando este não estiver compatível com o fundo para garantir a segregação dos elementos e a visibilidade.

Quanto à utilização de cores, temos uma aplicação negativa ao:

- Ignorar o significado e aplicação das cores padrões para determinadas funções institucionais como perigo, alerta e segurança.

- Usar em excesso a cor em informações irrelevantes, pois sobrecarrega e causa desconforto visual.

- Combinar cores indiscriminadamente ignorando o círculo cromático e o contraste entre: cores quentes, frias, análogas e complementares.

- Desconsiderar os fatores psicológicos das cores sobre as pessoas em detrimento a motivos apenas estéticos.

- Aplicar cores puras ou em tinta fluorescente em grandes áreas, para não prejudicar os aspectos da leitura e a compreensão da mensagem.

- Esquecer de destacar informações que precisam ser percebidas e passam despercebidas, pela falta ou excesso de contraste, reflexibilidade e fosforescência.

- Exagerar nas cores para chamar a atenção de várias áreas da tela ao mesmo tempo sem utilizar espaços em "branco" (vazios) que auxiliam na divisão da informação e arejamento visual.

As recomendações feitas por Ambrosa (2012) dizem respeito a:

- Utilizar imagens de forma estratégica, pois estas se comunicam com o receptor dependendo de como são apresentadas, e podem transmitir emoção ao projeto ou descontextualizá-lo.

- Apresentar um texto mal justificado pode separar as palavras em lugares irregulares com a hifenização. É preferível separar 


\section{$16^{\circ}$ \\ ERGODESIGN USIHC CINAHPA}

uma palavra em vez de criar um espaço exagerado.

- Aplicar recursos gráficos para dar ritmo à página e segmentar as informações, ou, ainda, inserir blocos coloridos para criar pontos finais visuais que levem o leitor a parar.

- Evitar utilizar palavras grandes e caixa alta, pois desencadeiam o escaneamento (isso quer dizer que o leitor não lerá necessariamente todas as palavras), enquanto o uso de fontes menores encoraja a leitura.

- Evitar muitas linhas de textos, pois estes tendem a ser escaneados em vez de lidos. Utilizar textos curtos, claros e objetivos.

- Usar da hierarquia de texto em títulos indicando níveis variados de importância, por meio do tamanho e/ou estilo.

Com base no exposto, ao elaborar mensagens informativas ou dialéticas em contextos educacionais é preciso que o profissional, segundo Robert Bringhurst (2011, p.28), "faça com que a relação visual entre texto e seus outros elementos (fotografias, legendas, tabelas, diagramas, notas) seja um reflexo de sua real relação". Assim, tudo deve estar em consonância com o conteúdo e o layout adotado de modo que o aluno perceba a complementação entre a informação escrita e simbólica de forma harmônica e consistente para evitar qualquer tipo de ruído.

E é neste trato virtual com os alunos que os profissionais da educação devem levar em consideração algumas funções que a tipografia bem aplicada numa mensagem deve ser capaz de fornecer. Ainda segundo Bringhurst (2011, p.31), algumas delas são: "convidá-lo à leitura; revelar o teor e o significado do texto; tornar clara a estrutura e a ordem do texto; e conectar o texto a outros elementos existentes".

Nesta ótica, a importância do uso de princípios ergonômicos em mensagens se amplia ao atendimento de alunos com possíveis restrições visuais, como baixa visão e daltonismo, tornando a comunicação muito mais acessível. $16^{\circ}$ Ergodesign - Congresso Internacional de Ergonomia e Usabilidade de Interfaces Humano Tecnológica: Produto, Informações Ambientes Construídos e Transporte

$16^{\circ}$ USIHC - Congresso Internacional de Ergonomia e Usabilidade de Interfaces Humano Computador

CINAHPA | 2017 - Congresso Internacional de Ambientes Hipermídia para Aprendizagem.

\section{Análise dos AVAs}

A partir do arcabouço teórico apresentado, este estudo objetivou identificar alguns problemas comunicacionais frequentes nas atividades dos profissionais envolvidos com a EaD. Para isso, foram acessados cinco AVAs diferentes, todos desenvolvidos na plataforma Moodle, associados a instituições de ensino da Grande Florianópolis. Apresentam-se, na sequência, oito imagens extraídas e derivadas destes ambientes, nas quais foram identificados aspectos onde o uso de recomendações de ergonomia visual poderia ter contribuído para a oferta de material de melhor qualidade técnica.

A Figura 1 ilustra uma situação em que ocorrem problemas visuais na apresentação de mensagem enviada pelo Moodle. A utilização de muitas cores diferentes prejudica a harmonia da mensagem e transmite pouca seriedade. Ao usar cores fluorescentes, há diminuição do conforto visual, pela vibração exagerada da cor no contraste figurafundo. Além disso, o uso de nomenclaturas aleatórias para imagens pode gerar ruídos na comunicação, como o "boca aberta" no final do texto, que apareceu, pois o gerenciador de e-mail bloqueou a imagem anexada. Neste caso, recomenda-se que se nomeiem as figuras a serem utilizadas de forma mais semântica para o usuário entender que se trata de uma imagem que não carregou (uma possibilidade seria usar imagem_aviso.jpg).

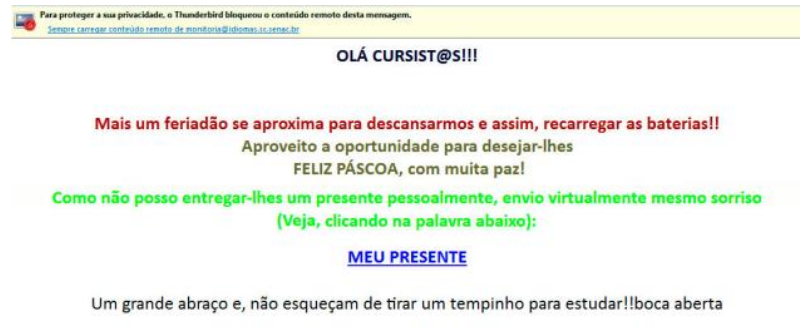

Figura 1: Envio de mensagem via Moodle Fonte: adaptado do Thunderbird via ead.sc.senac.br/idiomas (2014) 


\section{$16^{\circ}$ \\ ERGODESIGN USIHC CINAHPA}

Na Figura 2 ocorrem algumas inadequações pela falta de recursos visuais na tela de login do Moodle. Nesta situação, recomenda-se fazer uso de imagens e ícones para ilustrar as palavras "aviso" e "dica". A cor do link laranja em cima do fundo amarelo produz baixa visibilidade. O ideal é que o link seja azul, a menos que todos os demais tenham outra cor, garantindo a consistência.

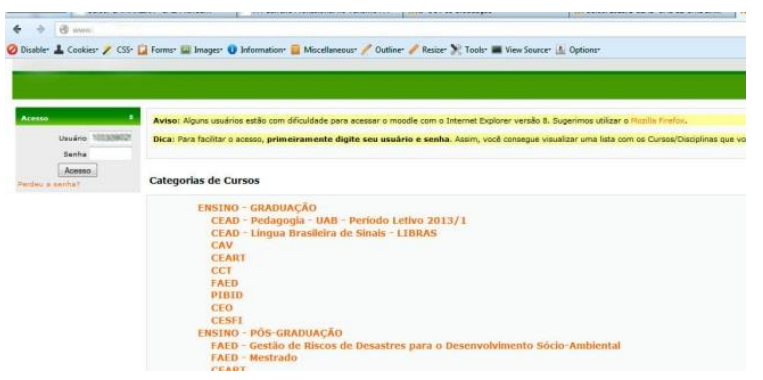

Figura 2: Recursos Visuais na tela de login Fonte: adaptado de moodle.udesc.br (2014)

Na Figura 3, o uso inadequado de recursos tipográficos para diferenciação de textos é um problema. Nesta situação, recomenda-se a utilização de recursos gráficos para dar destaque a determinadas informações, como linhas e imagens. A cor azul transmite tranquilidade, mas traz monotonia à informação, que deveria, na verdade, atrair e estimular o aluno.

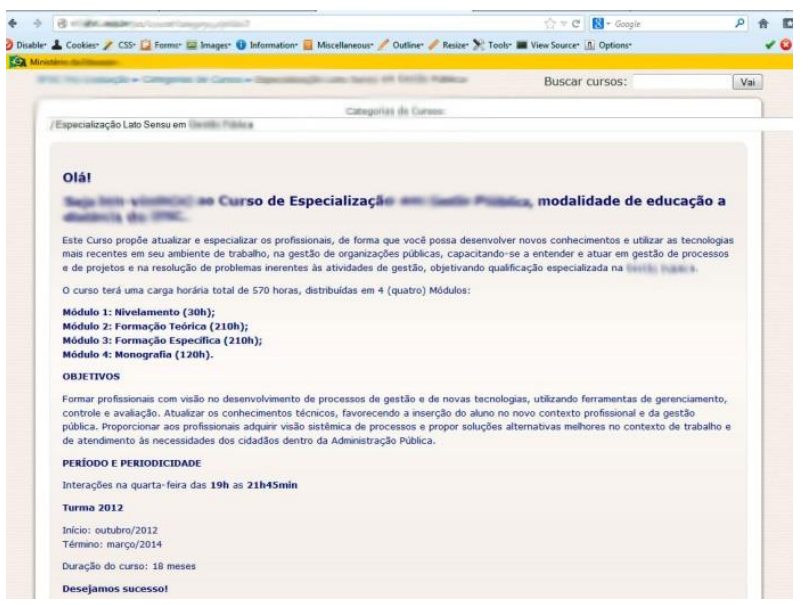

Figura 3: Recursos tipográficos

Fonte: adaptado de ead.ifsc.edu.br/pos (2014) $16^{\circ}$ Ergodesign - Congresso Internacional de Ergonomia e Usabilidade de Interfaces Humano Tecnológica: Produto, Informações Ambientes Construídos e Transporte

$16^{\circ}$ USIHC - Congresso Internacional de Ergonomia e Usabilidade de Interfaces Humano Computador

CINAHPA | 2017 - Congresso Internacional de Ambientes Hipermídia para Aprendizagem.

Na Figura 4, ocorrem problemas no uso inadequado de elementos visuais descontextualizados na sala do Moodle. Observase que o uso de animais e personagens de desenho devem ser evitados. Além disso, os textos devem ser inteligíveis. É importante evitar misturar assuntos diferentes em um mesmo espaço de publicação, como por exemplo, a mensagem do Adobe Flash no meio do conteúdo. Nesta situação, o ideal seria escolher imagens que sejam mais próximas da informação textual apresentada e demarcar em caixas a separação entre os assuntos distintos.

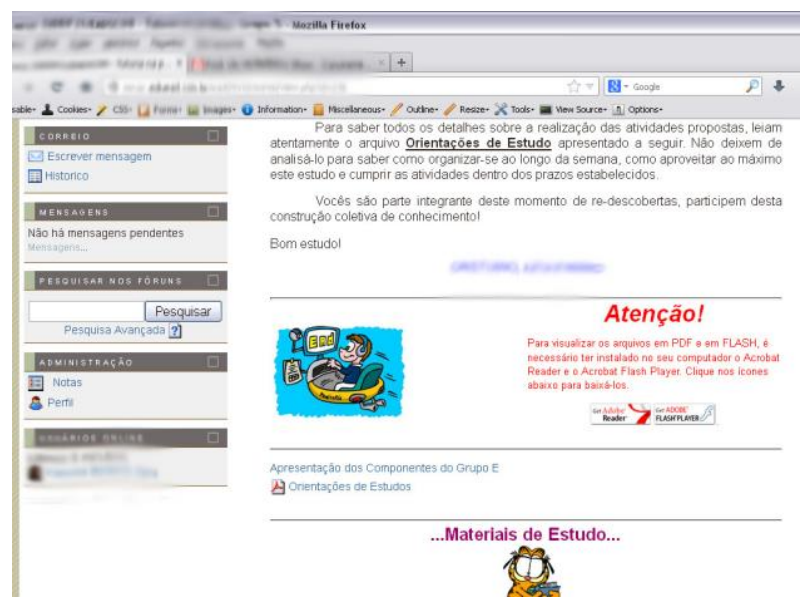

Figura 4: Imagens fora do contexto

Fonte: adaptado de senac.eduead.com.br/login (2014)

Na Figura 5, ocorrem problemas na organização das informações: faltam títulos para localizar o aluno no conteúdo; faltam cores para expressar e reforçar a informação visual; há ausência de um topo de apresentação com o nome da disciplina e elementos gráficos (como ícones, imagens e vídeos, contextualizando o curso), o que gera a impressão de um ambiente inacabado, pouco confiável. Nesta situação, recomenda-se o uso do apoio visual "ponto de entrada" para indicar por onde começar a leitura e contextualizar o aluno. E, ainda, ressalta-se a importância de utilizar rótulos informativos, datas, e textos introdutórios para cada aula realizada.
Realização:

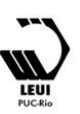




\section{$16^{\circ}$ \\ ERGODESIGN USIHC CINAHPA}

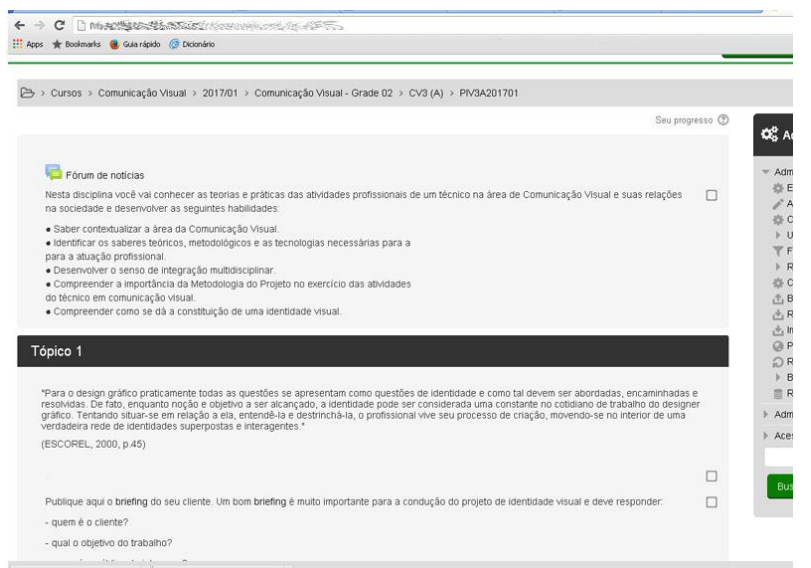

Figura 5: Elementos gráficos e estruturais Fonte: adaptado de moodle.palhoca.ifsc.edu.br (2017)

Na Figura 6, ocorrem problemas na formatação do texto da mensagem enviada para comunicação no e-mail: excesso de cores competindo com a atenção; corpo do texto longo, em caixa alta, durante a mensagem; baixo contraste entre o fundo e o texto do bloco "Espetáculo"; um texto sublinhado como se fosse um link e outro sublinhado sendo um link e variação de fonte tipográfica causando inconsistência a mensagem. Nesta situação, recomenda-se o uso coerente das cores, sem exagero, apenas para destacar itens de maior relevância na mensagem e ainda, a utilização do texto com apenas um tipo de fonte em caixa baixa.

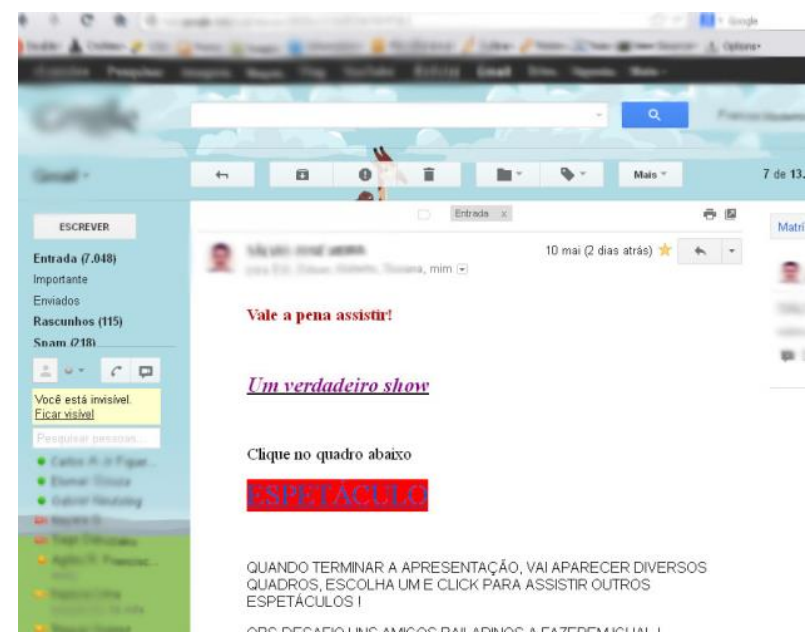

Figura 6: Recebimento de e-mail Fonte: adaptado de gmail.com (2014) $16^{\circ}$ Ergodesign - Congresso Internacional de Ergonomia e Usabilidade de Interfaces Humano Tecnológica: Produto, Informações Ambientes Construídos e Transporte

$16^{\circ}$ USIHC - Congresso Internacional de Ergonomia e Usabilidade de Interfaces Humano Computador

CINAHPA | 2017 - Congresso Internacional de Ambientes Hipermídia para Aprendizagem.

Na Figura 7, ocorrem problemas na formatação da tela de apresentação dos cursos no ambiente virtual: excesso de texto corrido em primeiro plano; excesso de blocos de cores puras e com grande saturação sem uma hierarquia das informações e distinção de relevância sobrecarrega o usuário. A falta de ilustrações e ícones também contribui para que seja pouco atrativo e não instigue a leitura. Nesta situação, recomendam-se o uso das cores apenas em alguns pontos de maior destaque, e o uso dos ícones para substituir o link "Mozila Firefox", os títulos de "dicas" e "avisos".

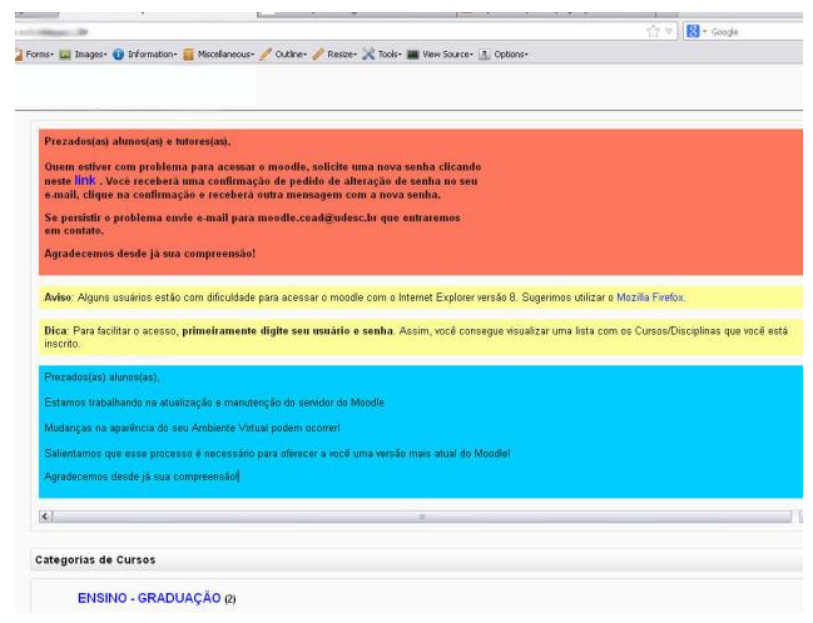

Figura 7: Tela de instruções e apresentação Fonte: adaptado de moodle.udesc.br (2014)

Na Figura 8, a tela inicial de apresentação dos cursos de especialização no ambiente virtual está bem organizada, porém também se pode levantar a presença de alguns problemas: o uso da cor do texto azul é muito próximo da cor utilizada para determinar os links clicáveis, não havendo distinção visual entre eles; A fluorescente da cor do título esta em desarmonia com as demais cores aplicadas nos blocos. Como são várias cores, a cor do título está disputando à atenção e causando desconforto visual. Nesta situação, recomenda-se o uso de cores bem distintas entre o corpo do texto e os links. O título pode ter o brilho diminuído para harmonizar a tela. 


\section{$16^{\circ}$ \\ ERGODESIGN USIHC CINAHPA}

$16^{\circ}$ Ergodesign - Congresso Internacional de Ergonomia e Usabilidade de Interfaces Humano Tecnológica: Produto, Informações Ambientes Construídos e Transporte

$16^{\circ}$ USIHC - Congresso Internacional de Ergonomia e Usabilidade de Interfaces Humano Computador

CINAHPA | 2017 - Congresso Internacional de Ambientes Hipermídia para Aprendizagem.

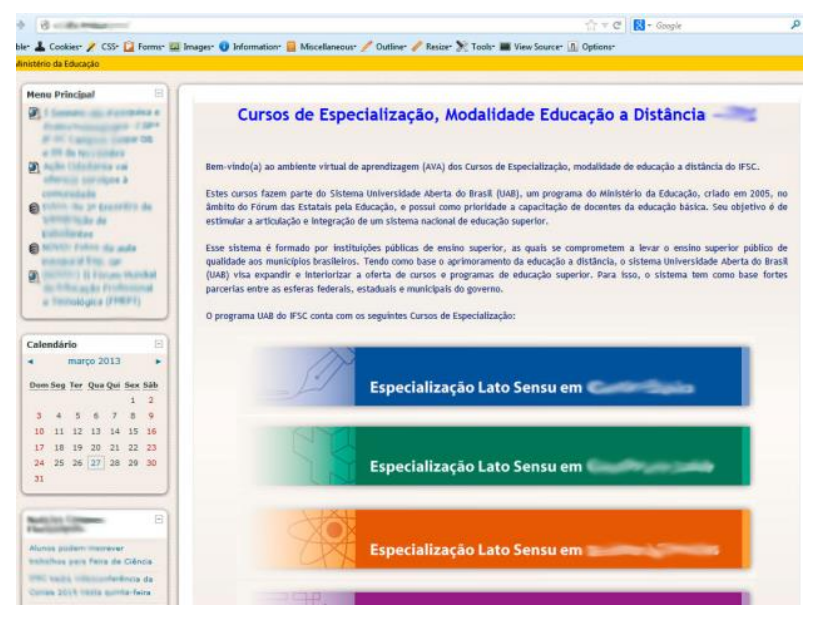

Figura 8: Tela de apresentação dos cursos Fonte: adaptado de ead.ifsc.edu.br/pos (2014)

\section{Considerações Finais}

A análise dos AVAs, neste artigo, possibilitou o diagnóstico de vários problemas relacionados à ergonomia visual, com base em conceitos estéticoformais, na comunicação no âmbito do ensino a distância, tais como a falta de domínio na utilização correta de cores, tipografias, proporção, elementos gráficos e, também falhar na organização e harmonia das informações.

Estas poucas situações, aliadas ao referencial teórico que foi apresentado neste artigo, permitem apontar a relevância do uso dos princípios ergonômicos na rotina didático-comunicativa em AVAs.

É necessário, portanto, saber utilizar elementos da tipografia, como negritos, sublinhados, tamanho de fontes, tipo de letra, família tipográfica, figurafundo, caixa alta, caixa baixa, alinhamentos, espaçamentos, círculo cromático, atrelados ao uso de imagens, de vídeos, de ícones e de animações que representam a construção de mensagens esteticamente mais atrativas, harmoniosas e coerentes, tanto com o layout quanto com o conteúdo. Os elementos de formatação visual apontados podem ser aplicados, no contexto dos AVAS, na EaD mediante a elaboração de mensagens, como de feedbacks e de avisos. Assim como, para a apresentação de informações, via $e$ mails, fóruns, chats, entre outros recursos disponíveis, que podem ser editados, como as salas de abertura dos cursos, os questionários e as wikis.

As reflexões geradas neste estudo contribuem para que se defenda a ideia de ofertar um curso de capacitação em Princípios Básicos de Ergonomia Visual, voltado aos profissionais do ensino a distância. Deste modo, ampliam-se as possibilidade de estes profissionais virem a maximizar a credibilidade da instituição que atuam, gerando empatia na disseminação de informações e na comunicação com os alunos. Porém, é válido ressaltar que, o acesso a essas informações e o domínio desse conhecimento não devem ser limitados apenas aos profissionais da educação (professores, tutores e designers instrucionais), mas sim disponibilizados a todos os envolvidos no processo de comunicação em meios digitais.

Nesta linha, o desenvolvimento de um curso estruturado com base nos conceitos visuais tipográfico, morfológico, cromático e tecnológico de Gomes (2010), é um caminho para aportar benefícios tanto para os educadores, quanto para os alunos. Os envolvidos na comunicação virtual teriam como estímulo sua atualização quanto ao uso das TICs e o aprimoramento de suas habilidades profissionais.

Sugere-se que novos estudos sejam realizados no sentido de mensurar a redução do tempo destinado ao preparo formal do conteúdo a ser exposto na internet, uma vez que a formação defendida anteriormente seja realizada. Além disso, conhecer melhor o benefício aportado aos alunos quando as informações estão melhor organizadas (as falhas no layout não chamam mais atenção do que o conteúdo, as mensagens tornam-se mais claras e objetivas) também é um tema que merece aprofundamento.

\section{Referências Bibliográficas}

ABRAHÃO, Júlia. Introdução à ergonomia: da prática à teoria. São Paulo: Blucher, 2009.

ABERGO. O que é ergonomia. Disponível em: 


\section{$16^{\circ}$ \\ ERGODESIGN USIHC CINAHPA}

$16^{\circ}$ Ergodesign - Congresso Internacional de Ergonomia e Usabilidade de Interfaces Humano Tecnológica: Produto, Informações Ambientes Construídos e Transporte

$16^{\circ}$ USIHC - Congresso Internacional de Ergonomia e Usabilidade de Interfaces Humano Computador

CINAHPA | 2017 - Congresso Internacional de Ambientes Hipermídia para Aprendizagem. <http://www.abergo.org.br/internas.php?pg=o_que e_ergonomia $>$. Acesso em: 25 de março de 2017.

AMBROSE, Gavin; HARRIS, Paul. Layout. Porto Alegre: Bookman, 2012.

AGNER, LUIZ. Ergodesign e arquitetura da informação: trabalhando com o usuário. 2. ed. Rio de Janeiro: Quartet, 2009.

AMOROSO, Danilo. O que é Web 2.0?

Tecmundo, 2008. Disponível em: <http://www.tecmundo.com.br/web/183-oque-e-web-2-0-.htm>. Acesso em: abril de 2013.

BATISTA, Claudia Regina; RIBAS Ulbricht, Vania. Discussões sobre o perfil do designer de interfaces web. Revista Design em Foco, vol. III, núm. 2, julio-diciembre, 2006, pp. 87-101

Universidade do Estado da Bahia Bahia, Brasil Disponível em:

$<$ http://www.redalyc.org/pdf/661/66111515007.pd f>. Acesso em: 24 de março de 2017.

BRINGHURST, Robert. Elementos do Estilo Tipográfico: versão 3.2. São Paulo: Cosac Naify, 2011.

GOMES, João Filho. Ergonomia do Objeto: sistema técnico de leitura ergonômica. 2. ed. São Paulo: Escrituras Editora, 2010.
GOMES, João Filho. Ergonomia e Design

Gráfico: sistema técnico de leitura ergonômica. Disponível em:

<http://joaogomes.com.br/ergonomia/ergonomia_d esign_grafico.pdf $>$. Acesso em: 24 de março de 2017.

GRUJIC, Andrej. Introdução ao Design. Web Design e Web Designer, 2008. Disponível em: <http://www.lsc.ufsc.br/ edla/design/web.htm>. Acesso em: outubro de 2012.

LITTO, Frederic M.; FORMIGA, Marcos.

Educação a Distância: O estado da arte. São Paulo: Pearson Education do Brasil, 2012.

MARTINS, Onilza Borges; POLAK, Ymiracy Nascimento de Souza. A Educação a Distância na Universidade Federal do Paraná: novos cenários e novos caminhos. Curso de aperfeiçoamento para capacitação de tutores em EaD. Curitiba: Editora da UFPR, 2001.

SANTAROSA, Lucila Maria Costi. Tecnologia e acessibilidade: passos em direção à inclusão escolar e sociodigital. Porto Alegre: Evangraf, 2014. 